\title{
Are there Hidden (Latent, Silent, Occult) Pancreatic Cancers?
}

\section{Parviz M Pour*}

UNMC Eppley Cancer Center, University of Nebraska Medical Center, Omaha, Nebraska, USA

\section{Case Blog}

According to a generally accepted theory [1,2] development of a tumor is the results of an arrest or blockage in the differential pathway of a given cell. Most neoplasms have a reasonably constant, exponential growth rate throughout the majority of their life span. This is an important biological feature in neoplasia because it predicts the length of time required for a single neoplastic cell to reach a mass of $1 \mathrm{~cm}$ in diameter. This is approximately 30 population doublings and is three times longer than the length of time required to grow from $1 \mathrm{~cm}$ to a near lethal $1 \mathrm{~kg}$ mass (which requires only an additional 10 population doublings). Thus, about $75 \%$ of the life span of (untreated) neoplasms occurs prior to development of symptoms, since small tumors are generally clinically silent. It is especially sobering to note that, on average, carcinomas require a metastatic phenotype (or characteristics) between the 8th and 12th population doubling. The actual amount of time between the inception of a neoplasm and its detection depends upon a number of factors including the doubling time of the tumor (which is a function of the tumor type, location, and grade) and the presence (or absence) of a promoting agent. For most common neoplasms, the interval between inception and clinical presentation may vary between 2 and 10 years, although this latency period is shortened (and the tumor yield increased) in the presence of promoting agents which are not, in of themselves, carcinogenic (or very weakly so) but greatly increase cellular growth in initiator-stimulated neoplastic tissue.

There is striking correlation between the physiologic turnover rates of normal cells and the doubling times (DTs) (the amount of time it takes for one cell or a group of cells to double in size) of neoplasms derived from cell population of that type. This supports the blocked ontogeny model of neoplasia since, to great extent, cell turnover rate is tissue determined. An additional bit of evidence favouring the maturation arrest theory is that cell types which do not cycle in postembryonic tissue, such as cerebral neurons or cardiac monocytes, never give rise to neoplasms in adults. These cell types lack a postembryonic stem cell population. Epithelial malignancies have a defined pre-invasive growth phase, an invasive (pre-metastatic) growth period and, often, a metastatic phase of growth. Thus, neoplasms evolve phenotypically, a phenomenon called tumor progression. As the blocked ontogeny model makes no explicit provision for phenotypic evolution, this theory may be difficult to reconcile with tumor progression. However, Pierce et al. have shown that the phenotype of the neoplastic population may evolve in response to environmental changes [1,2]. Indeed, these authors have been able to abrogate malignant phenotype of neoplastic cells by injecting them into developing blastocytes or primordial tissues. In other words, neoplasia represents an epigenetic process, at least in part and, under the proper environmental influences, may be reversible. Accordingly, the same tumor exposed to different environmental conditions grows differently, meaning that in some milieu it expands quickly while, in others, it may expand slowly or even stop growing and even, eventually, regress.

The pancreas, inherently, has a very low cell replication rate. Therefore, in the pancreas, tumors generally grow slowly though the growth rate can be accelerated by certain factors, e.g. dietary fat, obesity and exposure to promoting agents. In such an environment, the pancreatic islet cells become larger and produce even more growth factors such as insulin, IGF- 1 and TGF- $\alpha$ This is the fundamental reason why the growth and metastatic behavior of the same tumor in different individual varies. For example, an increase in the number of cancers in a geographic area, typically referred to as a 'cluster', suggests a probable genetic background influenced by environmental influences. Two excellent examples of this phenomenon are mammary and prostatic cancers. African men, as a population, have a low incidence of prostatic cancer. However, if they move to a geographic area with a high incidence of that tumor, their incidence of prostatic cancer increases indicating increased susceptibility to developing that cancer. The same is true for the breast cancer; the natural resistance of Chinese women against breast cancer is abolished when they adapt to the Western lifestyle.

The World Health Organization (WHO) has noted that, while the incidence of symptomatic prostate cancer is far greater in Western countries that in African countries, the actual rate of occult prostatic cancer, confirmed by autopsy analyses, is similar in both populations, indicating that any difference in the incidence rates is, in fact, relative.

In both populations cancer develops at the same rate but in African man the cancer remains occult while in American men it flourishes. This observation was confirmed by Franks [3], who performed a systematic analysis of prostate cancer in men undergoing autopsies and noted that $38 \%$ of men older than 50 years had microscopic prostate cancer. Sakr et al. [4] found that as many as $34 \%$ of men in their 40 s had early evidence of prostate cancer.

The same phenomenon has been observed in the pancreas, although the anatomic location and large size of the organ have hindered its thorough examination. Is there any evidence that, like in the prostate, cancers in the pancreas remain silent? There is indeed. Here is, thus far, 11 published cases.

1) In a study to examine the effects of cigarette smoking on the pancreas, we analyzed histopathologically 73 pancreases obtained at autopsy from 42 heavy cigarette smokers ( 20 or more cigarettes) and 31 non-smoker patients from veterans Hospital in Omaha, NE and from the University of Lund, Sweden [5]. The age of patients ranged from 35 to 93 years with median age of $69.4 \pm 11.2$ years in smokers and 66.5 \pm 13.0 years in non-smokers. There were 69 men and 4 women. The pancreases were examined thoroughly by taking tissues from different pancreatic areas and cutting them serially.

*Corresponding author: Parviz M Pour, UNMC Eppley Cancer Center, University of Nebraska Medical Center, Omah, Nebraska, USA, Tel: +1 4025594000; E-mail: ppour@unmc.edu

Received February 28, 2017; Accepted March 14, 2017; Published March 16, 2017

Citation: Pour PM (2017) Are there Hidden (Latent, Silent, Occult) Pancreatic Cancers? J Mol Biomark Diagn 8: 324. doi: 10.4172/2155-9929.1000324

Copyright: @ 2017 Pour PM. This is an open-access article distributed under the terms of the Creative Commons Attribution License, which permits unrestricted use, distribution, and reproduction in any medium, provided the original author and source are credited. 
Among the 42 smokers, $9.5 \%$ were noted to have subclinical, or 'silent', pancreatic cancers. One of the tumors was $2 \mathrm{~cm}$ in diameter while three were microcarcinomas between 2 and $5 \mathrm{~mm}$ in diameters. Of the three microcarcinomas one was located in the body of the pancreas in a 62-year-old man with lung cancer and two were located within the head of the pancreases of an 81-year-old man with colon cancer and a 61-year- old man with no other existing cancer. Each of these cancers was located in the periphery of the pancreas, remote from the main pancreatic duct. We also found in the 31 non-smokers an occult adenocarcinoma in the head of the pancreas from a 55 -year-old man who died of ethmoid cancer.

In addition to cancers, there were ductal changes, including mucinous hyperplasia (13 cases), squamous cell metaplasia (8 cases) and papillary hyperplasia (34 cases), alone or in combination in 50 out of 73 cases (68.5\%) including both smokers and non-smokers.

2) In yet another study, we conducted a thorough histological examination of pancreatic tissue procured from 83 military veterans, aged between 35 and 88 years of age, who had expired from conditions other than pancreatic cancer. We recorded hyperplastic, pre-neoplastic and neoplastic alterations by their severity, multiplicity, anatomic location and age of each patient [5,6]. Of the 83 cases studied, 3 (3.6\%) were found to have a primary pancreatic cancer. Two of these three pancreatic cancers were found in an 82-year-old and 55-year-old man while the third occult cancer was of the adenosquamous cell type and found in a 61-year-old man. The latter case led to the erroneous clinical diagnosis of lung cancer with metastases to the pancreas. Similar cases have also been reported [7].

3) In 78 cases without clinical evidence of pancreatic tumors, 4 men $(55,59,81$ and 82 years old) exhibited atypical ductal lesion and one man (48 years old) had a carcinoma in situ (today called a 'panIN 4') lesion. In all 4 cases, the carcinomas in situ were multifocal and all 4 patients had cancer of other sites [ear, prostate ( 2 cases) and colon].

4) In a more recent study, I found a microcystic adenoma in a donor's pancreas, which was used as a control pancreas, through serial sectioning. Our observations of occult hyperplastic, pre-neoplastic and actual neoplastic tissue in patients who expired from medical conditions other than pancreatic cancer, have been confirmed and reported by others.

5) Sommers et al. [7] found ductal epithelial hyperplasia in $41 \%$ of 141 pancreatic cancer specimens. In 4 of them, papillary hyperplasia, carcinoma in situ, and invasive carcinoma were found together in the same gland. This data compares to 150 autopsy pancreatic specimens in which only $9 \%$ were found to have ductal hyperplasia.

6) At the Peter Bent Brigham Hospital, histological examination of the whole pancreas removed for a cancer of the head of the gland revealed multifocal cancers in $37 \%$ of the patients [8]. Wilson and Imrie using ERCP detected an occult pancreatic carcinoma associated with recurrent pancreatitis [9].

7) Tomita et al, discovered a $0.9 \times 0.7 \times 0.7 \mathrm{~cm}$ tumor in a 27 -yearold white male with Lindau's disease, a rare, autosomal dominant genetic condition that predisposes individuals to benign and malignant tumors [10].

8) Compagno and Oertel [11] reported serous cystadenoma in 34 patients, including 10 incidental findings at autopsy.

9) In a study by Warshaw et al. [12], fully $33 \%$ of serous tumors referred to Massachussetts General Hospital had been misdiagnosed as pseudocysts.
Incidental pancreatic cysts are also commonly observed especially in older patients. They are commonly smaller than those cysts which result in symptoms and are unlikely to be pseudocysts. More than half of the are either malignant or pre-malignant lesions and therefore cannot be dismissed. [13] I agree with these authors when they state that, "The physician is more in need of a study that determines if IPMT (intraductal papillary mucinous tumors) or a mucinous cystic neoplasm is present rather than if it has become malignant, because based on current thinking, we know that all of these lesions are likely to progress to invasive cancer with time and therefore should be removed if the patient is an acceptable surgical candidate" [13]. Of course, such progression is hastened within all neoplasms by the presence of a promoting agent.

10). According to Lüttges et al. [14], of the 140 specimens diseasefree pancreas examined, 114 (81\%) showed ductal lesions, including mucinous cell hypertrophy (in 68\%), ductal papillary hyperplasia (in $36 \%$ ), adenomatoid ductal hyperplasia (in $40 \%$ ) and squamous cell metaplasia (in 36\%). 18\% of these lesions showed c-Ki-ras mutation, definitely pointing to their inherent malignancy. These "sleeping cancers", especially in diabetics who are poor on insulin, can awake fast when exposed to promoting growth factors produced by the $\beta$-cells. This is also the reason that pancreatic cancer in Type- 1 diabetes, who lack insulin production, is nearly non-existent.

11) Tada et al. [15] confirmed the presence of the c-Ki-ras mutation in 12 out of 38 patients with multiple ductal hyperplastic lesion.

12) In another study, not only c-Ki-ras mutation but also deletion of p16 and DPC4 [16], which are markers for advanced stages of the lesion (PAN-Ins 3-4).

13) More recently, we found an incidental cancer in a woman 73 -years of age who died of gastric cancer. This cancer, a glassy $11 \times$ $9 \times 9 \mathrm{~mm}$ multi-cystic lesion was found in the body of the patient's pancreas, again, on its periphery. And, in yet another woman (93 yearsof-age) who expired from renal cancer, we found a $2 \mathrm{~mm}$ glassy cyst in the body of her atrophic pancreas [17]. These two occult, silent pancreatic cancers were initially detected by a Japanese colleague of mine, a pathologist who dissects each pancreas quite thoroughly. Without such careful dissection, each of these cancers would have gone unnoticed. "Chance favours the prepared mind" and occult cancers of the pancreas will go unnoticed if the pancreatic tissue is not thoroughly examined during necropsy.

Case 1: Sections from the multi-cystic lesion in the body of the pancreas from the 73-year-old woman contained four cysts of various sizes. The largest cyst was $6 \times 3 \mathrm{~mm}$ in greatest dimension and the other smaller cysts with pancreatic tissue between the two cysts. We noted both normal-appearing epithelial tissue and tissue showing different degrees of cellular dysplasia, atypia and carcinoma in situ, even within the same cyst, consistent with there being a progression of pathology from normal tissue to panIN 1 through panIN 4 and frank neoplasm" Remarkably, a few pancreatic ducts within the intact parenchyma close to the cysts and up to $3 \mathrm{~mm}$ away from them also showed a focal or multifocal epithelial abnormality and carcinoma-in situ changes (17-20). A $2 \mathrm{~mm}$ to $3 \mathrm{~mm}$ thin fibrous tissue mantle surrounded the largest cyst. Approximately $0.5 \mathrm{~mm}$ away from the mantle, a $6 \times 2 \mathrm{~mm}$ T-shaped area of the pancreas was occupied by a well-differentiated adenocarcinoma. The cancer was limited within this area and had not extended beyond the pancreas, but had invaded a nerve (17-20). In two areas, the malignant glands were found within the islets, some of which were partially or almost totally replaced by cancer cells. Strikingly, as 
in our previous observation, endocrine cells were found within the malignant glands and altered epithelia of the cysts and ducts.

Case 2: In the body of the pancreas, two small cysts with greatest dimensions of $3.0 \mathrm{~mm}$ and $2.6 \mathrm{~mm}$, with a $5.0 \mathrm{~mm}$ area of normal pancreatic tissue between them, were found. The larger cyst, surrounded by a thick, fibrous mantle, showed a monolayer, regular epithelium with small, focal papillary excrescences but no cellular atypia. The smaller cyst had predominantly multilayered epithelium in which gland-withingland formation consistent with carcinoma in situ was noticeable. In one of the serial sections, the atypical epithelium extended in a tongue- like pattern into two-thirds of the thick, sclerotic mantle that surrounded the cyst, and showed cell atypia and a few mitotic figures at the end of the protrusion. At the two opposite sides of the cyst and beyond the sclerotic mantle, malignant glandular structures, occupying areas of $2.8 \mathrm{~mm} \times 0.7 \mathrm{~mm}$ and $1.2 \mathrm{~mm} \times 0.5 \mathrm{~mm}$, respectively, were detectable. In both areas, malignant glands were predominantly within islets, many of which were almost totally destroyed and contained only a few immunoreactive endocrine cells. Invasion of the perineurium and of the peri-pancreatic fatty tissue was evident at the site of the small cancer.

To our knowledge, our two cases were the smallest pancreatic carcinomas ever reported [17-20]. They had several noteworthy features, which, in many aspects, resembled findings in the hamster pancreatic carcinoma model [21-23]. The destruction of islets by cancer cells in both cases was striking and correlated with some experimental observations. In the hamster, pancreatic carcinoma model, ductal adenocarcinomas arise from ductal and ductular cells but develop predominantly within islets [19-21]. As in humans, the intraductal tumors grow slowly, extend and remain within the ductal boundary for some time. By contrast, the tumors of the experimental model that develop within islets are highly malignant from their inception [19-21]. The occurrence of malignant glandular structures within human islets has also been observed $[19,20]$, but the derivation of malignant cells from within islets is unknown. The presented cases strongly suggest the involvement of islet cells in human pancreatic carcinoma.

Perineural invasion (invasion of nerves within the pancreas), one of the most common patterns of pancreatic carcinoma, has not been previously reported in the early stages of cancer development, most likely due to the limited material available for examination. However, as in experimental pancreatic carcinogenesis, perineural invasion appears to be an early event. This important feature of pancreatic carcinoma has been largely neglected as a factor in the clinical staging of the disease, both in the Japanese and the International Union Against Cancer. We believe that this specificity of pancreatic cancer to invade nerves accounts for its high recurrence rate after surgery, as the Japanese surgeons have found that cancer cells reach the large ganglia (coeliac ganglia) en route of nerve fibers and remain there to explode [22,23].

It must again be emphasized that all of these occult, or silent, cancers were found only through thorough sectioning of the pancreases, suggesting that the incidence of hyperplasia, pre-neoplastic (including panIN 1-4) and neoplastic lesions exist in many, if not all pancreases, as humans age. It is of the utmost importance to understand that pancreatic cancer, despite its grave prognosis, may remain 'silent' for an unknown period of time including the remaining entirety of a patient's remaining lifespan. However, in the presence of promoting agents these silent lesions and cancers, more likely than not, respond and flourish much as smouldering members erupt into a raging fire in the presence of gasoline."

\section{References}

1. Sell S, Pierce GB (1994) Biology of disease: Maturation arrest of stem cell differentiation is a common pathway for the cellular origin of teratocarcinomas and epithelial cancers. Lab Invest 70: 6-21.

2. Sell S (2010) On the stem cell origin of cancer. Am J Pathol 176: 2584-2494.

3. Franks LM (1956) Latency and progression in tumors: the natural history of prostatic cancer. Lancet 2: 1037-1039.

4. Sakr WA, Haas GP, Cassin BF, Pontes JE, Crissman JD (1993) The frequency of carcinoma and intraepithelial neoplasia of the prostate in you male patients. J Urol 150: 379-385.

5. Tomioka T, Andrén-Sandberg A, Fujii H, Egami H, Takiyama Y, et al. (1990) Comparative histopathological findings in the pancreas of cigarette smokers and non-smokers. Cancer Lett 55: 121-128.

6. Kimura W, Morikane K, Esaki Y, Chan WC, Pour PM (1998) Histological and biological patterns of microscopic ductal adenocarcinomas detected incidentally at autopsy. Cancer 82: 1839-1849.

7. Sommers SC, Murphy SA, Warren S (1954) Pancreatic duct hyperplasia and cancer. Gastroenterology 27: 629

8. Collins JJ, Craighead JE, Brooks JR (1966) Rationale for total pancreatectomy for carcinoma of the pancreatic head. N Engl J Med 274: 599

9. Wilson C, Imrie CW (1986) Occult pancreatic cancer with recurrent acute pancreatitis. Postgrad Med J 62: 765-767.

10. Tomita T, Vacha E Rengachery S, Watanabe I (1978) Occult adenocarcinoma of the pancreas in a patient with Lindau's disease. Am J Dig Dis 23: 80-83.

11. Compagno, Oertel E (1978) Microcystic adenomas of the pancreas. A clinicopathologic study of 34 cases. AJCP 69: 289-298.

12. Warshaw A, Compton C, Lewandrowski K, Carde- nosa G, Mueller P (1990) Cystic tumors of the pancreas. Ann Surg 212:432-445.

13. Fernández-del Castillo, Targarona J, Thayer SP, Rattner DW, Brugge WR, et al. (2003) Incidental pancreatic cysts: Clinicopathologic characteristics and comparison with symptomatic patients. Arch Surg 138:427-434.

14. Lüttges J, Reinecke-Lüthge A, Möllmann B, Menke MA, Clemens A, et al. (1999) Ductal changes and K-ras mutations in the disease-free pancreas: analysis of type, age relation and spatial distribution. Virchows Arche 435: 461-468.

15. Tada M, Ohashi M, Shiratori Y, Okudaira T, Komatsu Y, t al. (1996) Analysis of Kras mutation in hyperplastic duct cells of the pancreas without pancreatic disease. Gastroenterology 110: 227-231.

16. Costentin L, Pagès $P$, Bouisson $M$, Berthelémy $P$, Buscail $L$, et al. (2002) Frequent deletions of tumor suppresoor genes in poure pancreatic juice from patients with tumoral or nontumoral pancreatic diseases. Pancreatology 2: 17-25.

17. Kimura W, Morikane K, Esaki Y, Chan WC, Pour PM (1998) Histological and biological patterns of microscopic ductal adenocarcinomas detected incidentally at autopsy. Cancer 82: 1839-1849.

18. Ariyama J, Suyama M, Ogawa K, Ikari T, Nagaiwa J, et al. (1990) The detection and prognosis of small pancreatic carcinoma. Int $\mathrm{J}$ Pancreatol 7: 37-47.

19. Manabe T, Miyashita T, Ohshio G, Nonaka A, Suzuki T, et al. (1988) Small carcinoma of the pancreas. Cancer 62: 135-141.

20. Sataka K, Chung YS, Umeyama K, Takeuchi T, Kim YS (1991) The possibility of diagnosing small pancreatic cancer (less than $4.0 \mathrm{~cm}$ ) by measuring various tumor markers. Cancer 68: 149-152.

21. Pour PM, Mohr U, Cardesa A, Althoff J, Krüger FW (1975) Pancreatic neoplasms in an animal model: Morphological, biological, and comparative studies. Cancer 36: 379-389.

22. Pour PM, Wilson R (1980) Experimental pancreas tumor. Cancer of the pancreas, Baltimore, Williams and Wilkins, USA 37-158.

23. Pour PM, Morohoshi T (1994) Ductal adenocarcinoma. Atlas of exocrine pancreatic tumors: Morphology, biology and diagnosis with an international guide for tumor classification. Tokyo: Springer-Verlag 117-154. 